\title{
Qualidade de sementes de arroz BRS jaçanã em função de aplicações de nitrogênio
}

\author{
Quality of BRS jaçanã rice seeds in response to application of nitrogen
}

Oscar José Smiderle ${ }^{[a]}$, Miguel Torres Chang ${ }^{[b]}$, Gilvan Barbosa Ferreira ${ }^{[c]}$,Antonio Carlos Centeno Cordeiro ${ }^{[a]}$

[a] Engenheiro agrônomo, DSc., pesquisador, Embrapa de Roraima, Boa Vista, RR - Brasil, e-mail: ojsmider@cpafrr.embrapa.br; acarlos@cpafrr.embrapa.br

[b] Engenheiro agrônomo, Universidade Federal de Roraima (UFRR), Boa Vista, RR - Brasil, e-mail: mtch_ufrr@yahoo.com.br

[c] Engenheiro agrônomo, DSc., pesquisador, Embrapa Algodão, Campina Grande, PB - Brasil, e-mail: gilvan.ferreira@cnpa.embrapa.br

\section{Resumo}

O nitrogênio é o nutriente mais absorvido pela cultura do arroz depois do potássio. Este trabalho foi realizado com o objetivo de avaliar a qualidade fisiológica de sementes de arroz irrigado, da cultivar BRS Jaçanã, produzidas em várzea de Roraima, em função de doses de nitrogênio e épocas de aplicação. Os tratamentos a que foram submetidas às plantas constam de quatro épocas de aplicação do nitrogênio em faixas (I - 50\% na semeadura e $50 \%$ aos 45 dias após a emergência - dae; II - 50\% aos 15 dae e $50 \%$ aos 45 dae; III - 100\% aplicado aos 15 dae e IV - 100\% aplicado aos 45 dae), aleatorizando-se nas faixas as doses de nitrogênio (50, 100,150 e $200 \mathrm{~kg} \mathrm{ha}^{-1}$ ). A semeadura em campo para a produção das sementes foi em parcelas subdivididas com delineamento em blocos ao acaso, com 16 tratamentos e quatro repetições. As sementes produzidas foram colhidas manualmente, trilhadas, secas e armazenadas em laboratório. Amostras das sementes foram avaliadas quanto à qualidade fisiológica, medindo-se a massa de 100 sementes, a umidade, o vigor e a germinação. As épocas de aplicação de nitrogênio modificam a qualidade fisiológica das sementes. A aplicação de metade da dose de nitrogênio na semeadura e a outra, aos 45 dias após a emergência, provocam redução na emergência de plantas em campo. A máxima qualidade fisiológica das sementes é obtida com a aplicação de $108 \mathrm{~kg} \mathrm{ha}^{-1}$ de nitrogênio em cobertura, aplicado todo aos 45 dias da emergência das plantas.

Palavras-chave: Oryza sativa. Massa de 100 sementes. Vigor. Germinação.

\section{Abstract}

Nitrogen is the most absorbed nutrient by rice crop, after potassium. This study was performed with the objective of assessing seed physiologic quality of BRS Jaçanã irrigated rice cultivar, cultivated in lowland of Roraima in response to Nitrogen doses and times of application. The treatments that plants were exposed to consisted of 
4 periods of Nitrogen stripe application (i. 50\% at sowing and 50\% 45 days after emergency - dae; ii. $50 \% 45$ dae; iii. 100\% applied 15 dae and iv. 100\% applied 45 dae), Nitrogen doses being randomly displayed within stripes (50, 100, 150 and $200 \mathrm{~kg} \mathrm{ha}^{-1}$ ). Field planting for seed production was performed as split-plot, under a completely randomized block experimental design, with 16 treatments and four replicates. Produced seeds were manually harvested, threshed, dried and stored in laboratories. Seed samples were assessed according to physiologic quality, by measuring mass of 100 seeds, humidity, vigor and germination. Times of Nitrogen application modify seed physiologic quality. Applying half dose of Nitrogen at sowing and the other half 45 dae cause bed plant emergency reduction. Maximum seed physiologic quality is obtained with dressing application of $108 \mathrm{~kg} \mathrm{ha}^{-1}$ Nitrogen, applied in unique dose 45 dae.

Keywords: Oryza sativa. Mass of 100 seeds. Vigor. Germination.

\section{Introdução}

No Brasil, o arroz é uma das mais importantes culturas anuais, ocupando posição de destaque do ponto de vista econômico e social, com presença na dieta de muitos brasileiros. Assim como a maioria das culturas, tem no nitrogênio e no potássio os nutrientes mais absorvidos. Depois do K, o N é o nutriente mineral que a planta de arroz mais acumula. $\mathrm{O} \mathrm{N}$ é componente estrutural importante da planta fazendo parte de aminoácidos, proteínas, enzimas, membranas e ácidos nucléicos (MARSCHNER, 1995). Em teor adequado no tecido, o nutriente aumenta a área foliar da planta, melhora a eficiência de interceptação da radiação solar e a taxa fotossintética, provoca aumento do número de perfilhos, número de panículas, número de grãos e tamanho dos grãos, o que reflete no aumento de produtividade.

Estudos mostram que o nitrogênio é um dos elementos limitantes para o cultivo do arroz em várzeas (SILVA; MELO; MEDEIROS, 1998). Para tal, exige aplicação de elevadas doses para que ocorra o desenvolvimento adequado da cultura em termos de perfilhamento e produtividade de grãos (BARBOSA FILHO, 1987). Além disso, a resposta da cultura à aplicação de nitrogênio depende das condições climáticas e do tipo da planta (MACHADO, 1985). Para os cultivos comerciais no Estado de Roraima aplicase de 100 a $200 \mathrm{~kg} \mathrm{ha}^{-1}$ de $\mathrm{N}$.

Apenas os fertilizantes amoniacais ou formadores de amônio, como a ureia, são recomendados no cultivo de arroz irrigado por alagamento do solo (SOSBAI, 2005). A ureia destaca-se pelo elevado conteúdo de nitrogênio $(\mathrm{N})$ e menor custo por unidade do nutriente aplicado, razões que a tornam a principal fonte de $\mathrm{N}$ para a cultura. No entanto, esse fertilizante apresenta reação inicial alcalina no solo, favorecendo as perdas por volatilização de amônia, processo cuja intensidade varia em função das condições climáticas, atributos do solo e de práticas de manejo. Em cultivo irrigado, a ureia aplicada em cobertura se dissolve na lâmina de água de irrigação com perdas insignificantes de amônia.

O nitrogênio é de fundamental importância na cultura do arroz irrigado, pois promove melhor desenvolvimento da planta, aumentando a produção de palha, o número de panículas por unidade de área e desempenhando papel importante na formação de órgãos reprodutivos e dos grãos. Dentre vários fatores que afetam a utilização do nitrogênio, a cultivar utilizada merece atenção especial. Fageria e Barbosa Filho (1982), em seu trabalho, evidenciaram diferenças entre cultivares de arroz irrigado. Thakur (1993) também verificou que cultivares de arroz se comportaram de modo diferencial para a aplicação de nitrogênio para produtividade de grãos. Reis et al. (2005) obtiveram respostas diferenciais para as doses crescentes de $\mathrm{N}$ (800 mg de $\mathrm{N} \mathrm{kg}^{-1}$ de solo) nas cultivares estudadas, e com a Capivari verificaram maior absorção de macronutrientes que a Inca e a Sapucaí. Carvalho et al. (1995) constataram que em condições favoráveis as cultivares melhoradas de arroz irrigado respondem positivamente à aplicação de nitrogênio.

A dose adequada é aquela quantidade de nutriente que propicia produção econômica e acima da qual não há resposta lucrativa da cultura, para o produtor, que justifique aumentar a quantidade do nutriente (STONE et al., 1999). As recomendações de adubação nitrogenada são feitas com base na resposta da cultura à aplicação desse nutriente em condições de 
campo (FAGERIA et al., 2003). $0 \mathrm{~N}$ é um nutriente móvel no sistema solo-planta e se perde facilmente por lixiviação, volatilização e desnitrificação, de modo que o parcelamento durante o ciclo da cultura pode aumentar sua eficiência de utilização. A disponibilidade do nutriente na concentração e na época adequada, quando a cultura precisa dele em maior quantidade durante o seu ciclo, é importante para aumentar a sua eficiência de absorção e utilização.

A BRS Jaçanã é uma nova cultivar desenvolvida pela Embrapa, sendo indicada para cultivos irrigados em Roraima (CORDEIRO; MEDEIROS, 2008). Ela se destaca pela resistência ao acamamento, curto período de maturação de pós-colheita e alto rendimento de grãos inteiros. Entretanto, o efeito da adubação nitrogenada sobre a qualidade fisiológica da semente ainda não foi estudado adequadamente.

Lopes e Grabe (1973), procurando caracterizar a influência da origem da semente sobre sua qualidade fisiológica, argumentaram que um dos aspectos a ser levado em consideração é o relacionado com o conteúdo de proteínas das sementes, pois condições ambientais diferentes podem originar sementes com diferentes teores proteicos; isso possivelmente afeta a sua qualidade. No entanto, Fox e Albrecht (1957) não detectaram influência significativa das diversas épocas de aplicação de nitrogênio sobre o vigor das sementes e mencionaram, ainda, que a aplicação tardia de nitrogênio sobre plantas de trigo condicionou a produção de sementes com baixa velocidade de emergência.

Assim, este trabalho foi realizado com o objetivo de avaliar a qualidade fisiológica de sementes de arroz irrigado cultivar BRS Jaçanã em função de doses de nitrogênio e épocas de aplicação.

\section{Materiais e métodos}

As sementes avaliadas no Laboratório de Análise de Semente e em canteiro telado, ambos pertencentes à Embrapa Roraima, em Boa Vista, foram produzidas em área experimental, localizada na várzea do Rio Branco, na Fazenda Santa Cecília, no município do Cantá, Roraima (2 48' 27,484" N e 60³9' $17^{\prime} 564^{\prime \prime} \mathrm{W}$ ), no período de dezembro de 2007 a março de 2008, em solo do tipo gleissolo háplico tb distrófico, com as seguintes características químicas e físicas na camada de $0-20 \mathrm{~cm}: \mathrm{pH}=5,2 ; \mathrm{Ca}=0,64$ cmolc $\mathrm{dm}^{-3} ; \mathrm{Mg}=0,28 \mathrm{cmolc} \mathrm{dm}^{-3} ; \mathrm{K}=0,07 \mathrm{cmolc}$ $\mathrm{dm}^{-3} ; \mathrm{Al}=1,83 \mathrm{cmolc} \mathrm{dm}^{-3} ; \mathrm{P}=2,16 \mathrm{mg} \mathrm{dm}^{-3}$; matéria orgânica $=11,9 \mathrm{~g} \mathrm{dm}^{-3}$; areia $=7 \mathrm{dag} \mathrm{kg}^{-1}$; silte $=$ 50 dag $\mathrm{kg}^{-1}$; e argila $=43 \mathrm{dag} \mathrm{kg}^{-1}$.

0 delineamento experimental utilizado no cultivo no campo se deu em parcelas subdivididas com as parcelas distribuídas conforme o delineamento de blocos ao acaso, em quatro repetições, totalizando 64 unidades experimentais. Nas parcelas foram testadas as épocas de aplicação; e nas subparcelas, as doses de nitrogênio. As parcelas tiveram as dimensões de $4,20 \mathrm{~m} \times 14,00 \mathrm{~m}\left(58,80 \mathrm{~m}^{2}\right)$ e as subparcelas, as dimensões de $4,20 \mathrm{~m} \times 3,00 \mathrm{~m}\left(12,60 \mathrm{~m}^{2}\right)$, com área útil de 3,60 $\mathrm{m} \times 2,00 \mathrm{~m}\left(7,20 \mathrm{~m}^{2}\right)$. A semeadura foi realizada em linhas espaçadas de $0,3 \mathrm{~m}$ na densidade de $120 \mathrm{~kg} \mathrm{ha}^{-1}$ de sementes. Foi utilizada a cultivar de arroz irrigado BRS Jaçanã, lançada para cultivo em área de Cerrado de Roraima por Cordeiro e Medeiros (2008).

Os tratamentos constaram de quatro doses de nitrogênio: 50, 100, 150 e $200 \mathrm{~kg} \mathrm{ha}^{-1}$ de $\mathrm{N}$ (usando ureia como fonte), combinadas com quatro épocas de aplicação em cobertura: E1 = metade da dose na semeadura e metade aos 45 dias após a emergência (dae); E2 = metade da dose aos 15 e metade aos 45 dae; E3 = uma aplicação aos 15 dae e; E4 = uma aplicação aos 45 dae.

A adubação usada como básica na semeadura, para todos os tratamentos avaliados, constou de $450 \mathrm{~kg} \mathrm{ha}^{-1}$ de fórmula 04-28-20+ 0,5 \% de Zn. 0 sistema de irrigação utilizado foi por inundação contínua, com lâmina de água iniciada aos 15 dias após a emergência das plântulas e interrompida aos 20 dias após o completo florescimento.

Das sementes colhidas foi retirada uma amostra de 1,0 kg de cada unidade experimental, para levar ao LAS da Embrapa Roraima. Dessas amostras foram separadas e pesadas 8 repetições de 100 sementes, para obter a massa de 100 sementes, seguindo-se a determinação da umidade (BRASIL, 2009) para correção dos valores obtidos para 13\%. Avaliou-se, também, a germinação e a primeira contagem de germinação (vigor). Para isso, foram separadas 4 repetições de 100 sementes e colocadas para germinar em papel de germinação pré-umedecido com água destilada e, em seguida, acondicionadas em câmara de germinação, sendo as contagens realizadas conforme Brasil (2009). Determinou-se também a emergência de plântulas em canteiro conforme as regras para análise de sementes (BRASIL, 2009). 
As análises de variância foram realizadas para os dados de cada característica avaliada. Para comparação da qualidade fisiológica de sementes e eficiência de utilização de nitrogênio, foi utilizado o teste de Tukey $(\mathrm{p}<0,05)$; e para respostas às dosagens de nitrogênio, utilizou-se análise de regressão, aceitando-se até o $2^{\underline{o}}$ grau como significativo. Pelas equações de regressão obtidas para qualidade fisiológica de sementes, estimaram-se as doses de nitrogênio correspondentes aos valores máximos de cada variável medida.

\section{Resultados e discussão}

A época de aplicação e as doses de nitrogênio afetaram de forma diferenciada as variáveis que caracterizam a qualidade da semente. Não houve nenhum efeito sobre a massa de 100 grãos, porém a umidade, a primeira contagem de germinação, a germinação e a emergência em canteiro foram afetadas tanto pela época como pelas doses de aplicação do nitrogênio durante o cultivo do arroz em área de várzea de Boa Vista (Tabela 1).

A aplicação parcelada da adubação nitrogenada, metade na semeadura ou aos 15 dias após a emergência (dae), complementada com outra metade aos 45 dae, nos resultados médios obtidos em termos gerais, aumentou o grau de umidade nas sementes obtidas (Tabela 2), sendo o acréscimo superior a $0,25 \%$, limite aceito em função dos dados coletados. Entretanto, apenas as aplicações de doses crescentes do nutriente realizadas na época 1 permitiram aumentos lineares na umidade da semente (Gráfico 1). Para essa época, o aumento da dose de $\mathrm{N}$ aplicada de 50 para $200 \mathrm{~kg} \mathrm{ha}^{-1}$ resultou em sementes com $10,8 \%$ e $11,2 \%$ de umidade, respectivamente.

As épocas de adubação e as doses testadas neste trabalho tiveram influência sobre o vigor, obtido pela determinação na primeira contagem de germinação (PCG) das sementes (Tabela 2). Em geral, as plantas que foram adubadas em cobertura aos 15 dias da semeadura tiveram sementes mais vigorosas que as demais, especialmente quando a aplicação foi efetuada em dose única. As plantas de arroz tendem a ter um crescimento vegetativo mais equilibrado quando adubadas próximo do perfilhamento, o que pode limitar o número de perfilhos, os quais são definidos entre 14 e 42 dias após a emergência das plântulas (STANSEL, 1975). Provavelmente, a planta produziu maior área foliar e, com isso, possibilitou melhora nas características da composição química, em quantidade e equilíbrio, das sementes com substâncias de reserva, tornando sua germinação mais vigorosa. Segundo Schuch e Mundstock (1994), aplicações parceladas de nitrogênio, sincronizadas com os períodos de maior demanda pela planta, aumentam a eficiência no uso do fertilizante. 0 maior vigor alcançado $(64,0 \%)$ é visualizado no Gráfico 2 e ocorreu na época E1, com o uso de $123 \mathrm{~kg} \mathrm{ha}^{-1}$ de $\mathrm{N}$; na sequência, vieram as épocas E3 (63,2\%, com $108 \mathrm{~kg} \mathrm{ha}^{-1}$ de N), a E4 (59,3\%, com $113 \mathrm{~kg}$ ha $^{-1}$ de N) e a E2 (58,9\%, com $167 \mathrm{~kg} \mathrm{ha}^{-1}$ de N). Considerando o desvio mínimo significativo (DMS) de 3,05\% (Tabela 2), as épocas E1 e E3 permitiram a obtenção de vigores semelhantes entre si e superiores aos demais. Dessa forma, a adubação feita na época E3 teve maior efetividade sobre esse componente de qualidade da semente.

A germinação das sementes, embora elevada nos tratamentos, foi afetada pelas épocas e doses de aplicação de nitrogênio e as épocas E2 e E4 foram superiores às demais (Tabela 2). Contudo, apenas nas épocas 1 e 2 foi verificada resposta diferenciada em relação às doses de nitrogênio aplicadas (Gráfico 3). Isso possivelmente deve-se ao tempo necessário para o nutriente ser absorvido pelas plantas, metabolizado e translocado até as sementes dessa cultivar, podendo ser diferenciado de outras, conforme verificado por Jiang et al. (2004), em três diferentes cultivares de arroz. Na época E1, 99,5\% de germinação foi alcançada com uso de $105 \mathrm{~kg} \mathrm{ha}^{-1}$ de $\mathrm{N}$; já na época E2, foram necessários $135 \mathrm{~kg} \mathrm{ha}^{-1}$ de $\mathrm{N}$ obtendo 98,1\% de germinação. Assim, a adubação nitrogenada feita na época E1 tende a ser mais efetiva sobre a germinação.

A emergência de plantas em canteiro foi afetada pelas épocas de aplicação e pelas doses de nitrogênio, alcançando maiores valores quando feitas nas épocas E2 a E4 (Tabelas 1 e 2). A adubação feita na época E1 resultou em baixa emergência de plântulas em canteiro, inferior em relação às demais. Isso mostra que a adubação nitrogenada feita a partir de 15 dae, seja de forma parcelada ou em dose única, tem maior capacidade de influenciar a emergência de plântulas em canteiro. Apesar disso, somente houve resposta à aplicação de nitrogênio quando feita dentro das épocas E1, E2 e E4. Nesse caso, respostas 
Tabela 1 - Análise de variância para massa de 100 sementes (M100S em g), umidade (\%), primeira contagem de germinação (PCG \%), germinação (\%) e emergência de plantas em canteiro (EC \%) em sementes de arroz irrigado cv BRS Jaçanã, produzidas em função de épocas de aplicação e doses de nitrogênio, em área de várzea de Roraima - 2008

\begin{tabular}{|c|c|c|c|c|c|c|}
\hline \multirow[b]{2}{*}{ FV } & \multirow[b]{2}{*}{ GL } & \multicolumn{5}{|c|}{ Quadrado médio do resíduo } \\
\hline & & M100S & Umidade & PCG & Germinação & EC \\
\hline REP & 3 & 0,001 ns & 0,153 ns & 21,792 ns & 3,474 ns & 114,833 ns \\
\hline EP & 3 & 0,009 ns & $0,464 * * *$ & $71,875^{* * *}$ & $46,391 \quad * * *$ & $2331,625^{* * *}$ \\
\hline N/EP 1 & & & & & & \\
\hline$N$ & 3 & 0,003 ns & $0,230 *$ & $396,729^{* * *}$ & $141,229 * * *$ & $229,563 *$ \\
\hline Linear & 1 & 0,006 ns & $0,589^{* *}$ & 1,513 ns & $195,313 * * *$ & 6,613 ns \\
\hline Quadrático & 1 & 0,001 ns & 0,041 ns & $1139,062^{* * *}$ & $203,0633^{* * *}$ & 663,063 ** \\
\hline Cúbico & 1 & 0,002 ns & 0,061 ns & 49,613 * & $25,313 *$ & 19,013 ns \\
\hline N/EP $\quad 2$ & & & & & & \\
\hline $\mathrm{N}$ & 3 & 0,051 ns & 0,088 ns & $240,667^{* * *}$ & 20,417 ** & $442,729 * *$ \\
\hline Linear & 1 & 0,000 ns & 0,000 ns & 0,200 ns & 7,200 ns & $357,013 *$ \\
\hline Quadrático & 1 & 0,001 ns & 0,198 ns & $576,000^{* * *}$ & $36,000^{* *}$ & $715,5633^{* *}$ \\
\hline Cúbico & 1 & 0,014 ns & 0,066 ns & $145,800^{* * *}$ & $18,050^{*}$ & 255,6130 \\
\hline N/EP 3 & & & & & & \\
\hline$N$ & 3 & 0,006 ns & 0,129 ns & $150,667^{* * *}$ & 3,229 ns & 11,500 ns \\
\hline Linear & 1 & 0,005 ns & 0,125 ns & $156,800^{* * *}$ & 0,013 ns & 0,450 ns \\
\hline Quadrático & 1 & 0,001 ns & $0,238^{\circ}$ & $256,000^{* * *}$ & 3,063 ns & 0,250 ns \\
\hline Cúbico & 1 & 0,001 ns & 0,025 ns & 39,200 * & 6,613 ns & 33,800 ns \\
\hline N/EP 4 & & & & & & \\
\hline $\mathrm{N}$ & 3 & 0,007 ns & 0,025 ns & $157,229^{* * *}$ & 3,563 ns & $187,083 \quad 0$ \\
\hline Linear & 1 & 0,004 ns & 0,003 ns & $117,613^{* *}$ & 9,113 ns & $231,200 \quad 0$ \\
\hline Quadrático & 1 & 0,009 ns & 0,065 ns & $333,063^{* * *}$ & 1,563 ns & $324,000^{*}$ \\
\hline Cúbico & 1 & 0,006 ns & 0,007 ns & 21,013 ns & 0,013 ns & 6,050 ns \\
\hline Resíduo & 45 & 0,008 & 0,069 & 10,469 & 4,252 & 72,889 \\
\hline CV(\%) & & 2,987 & 2,436 & 5,883 & 2,168 & 13,034 \\
\hline
\end{tabular}

Legenda: Legenda: ns, ${ }^{\circ},{ }^{*},{ }^{* *} \mathrm{e}^{* * *}$ : não significativo e significativo a $10 \%, 5 \%, 1 \%$ e $0,1 \%$ de probabilidade pelo teste $\mathrm{F}$.

Fonte: Dados da pesquisa.

máximas de $55,3 \%$, $82,4 \%$ e $76,6 \%$ foram obtidas com uso das doses de 122, 140 e $108 \mathrm{~kg} \mathrm{ha}^{-1}$ de nitrogênio, respectivamente (Gráfico 4). Como a DMS foi de $8,05 \%$ (Tabela 2), a dose de $108 \mathrm{~kg} \mathrm{ha}^{-1} \mathrm{de}$ nitrogênio na época $\mathrm{E} 4$ foi a mais efetiva sobre a emergência em canteiro, alcançando valores estatisticamente equivalentes aos obtidos na E2, com uso de $140 \mathrm{~kg} \mathrm{ha}^{-1}$ do nutriente. A adubação na época E4 foi realizada em dose única aos 45 dae ou pleno florescimento. É esperado que a adubação tardia com $\mathrm{N}$ nas gramíneas, em geral, aumente o teor de proteína nas sementes e isso pode ajudar na preservação das membranas celulares dos tecidos de reserva e aumentar o teor de proteína e/ou a atividade enzimática na semente em processo de germinação. Essas atividades podem ajudar na maior emergência em canteiro e na produção de grãos com maior teor proteico. 


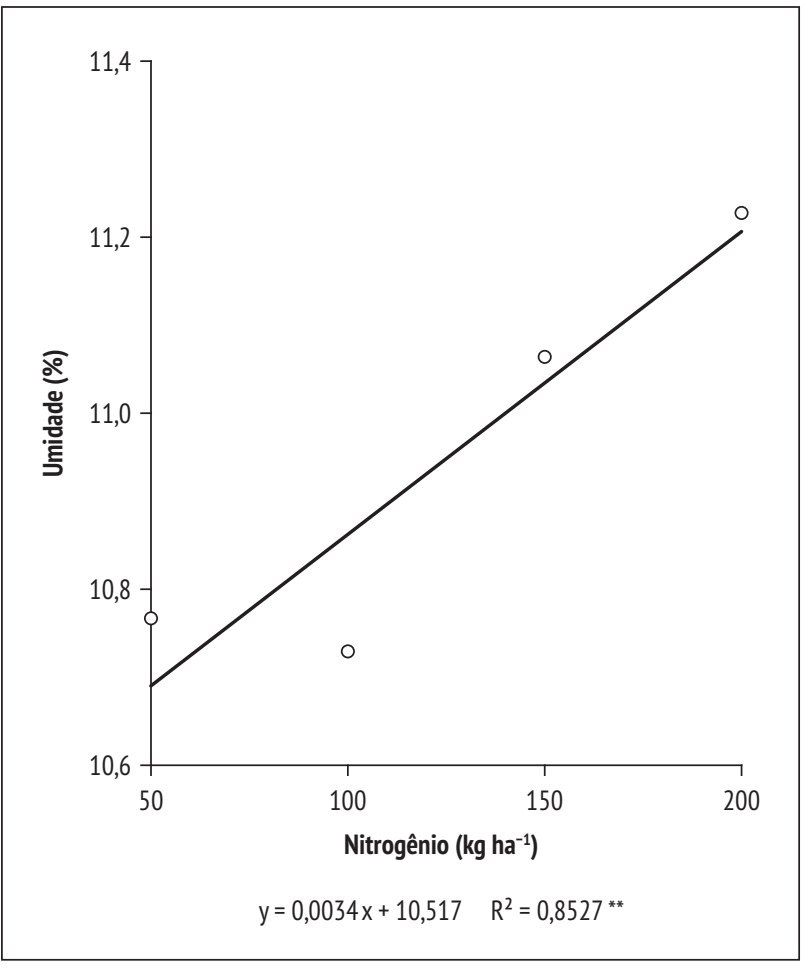

Gráfico 1 - Variação do grau de umidade em sementes de arroz irrigado (cultivar BRS Jaçanã) em função de doses de nitrogênio aplicadas

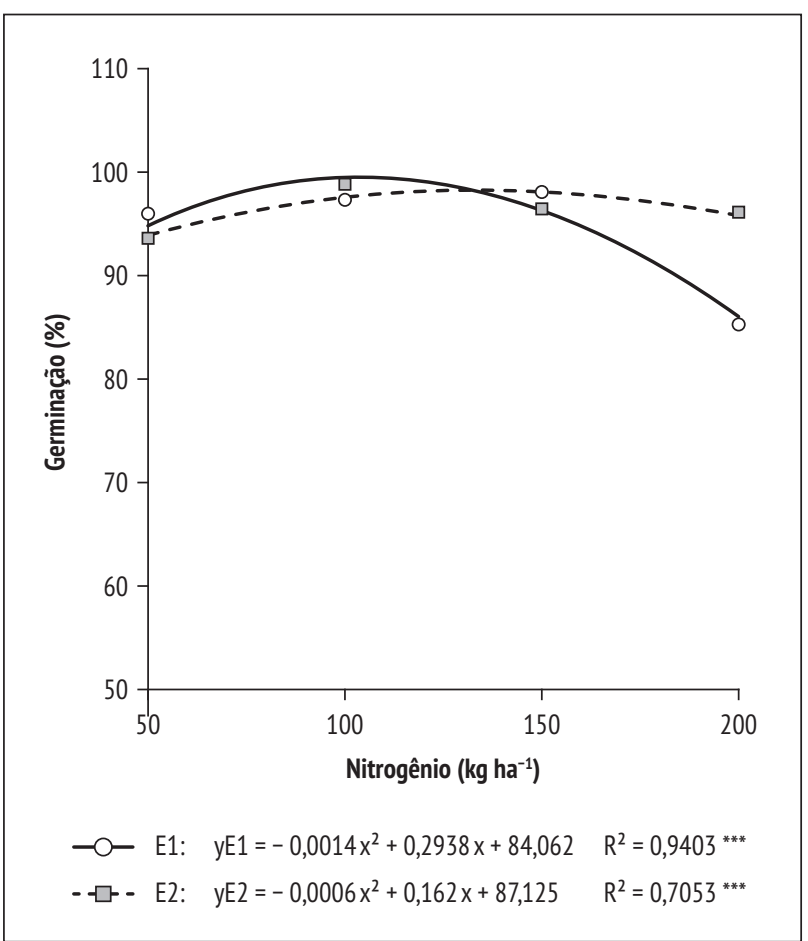

Gráfico 3 - Variação na germinação em função de épocas e doses de nitrogênio em sementes de arroz irrigado BRS Jaçanã produzidas em Roraima

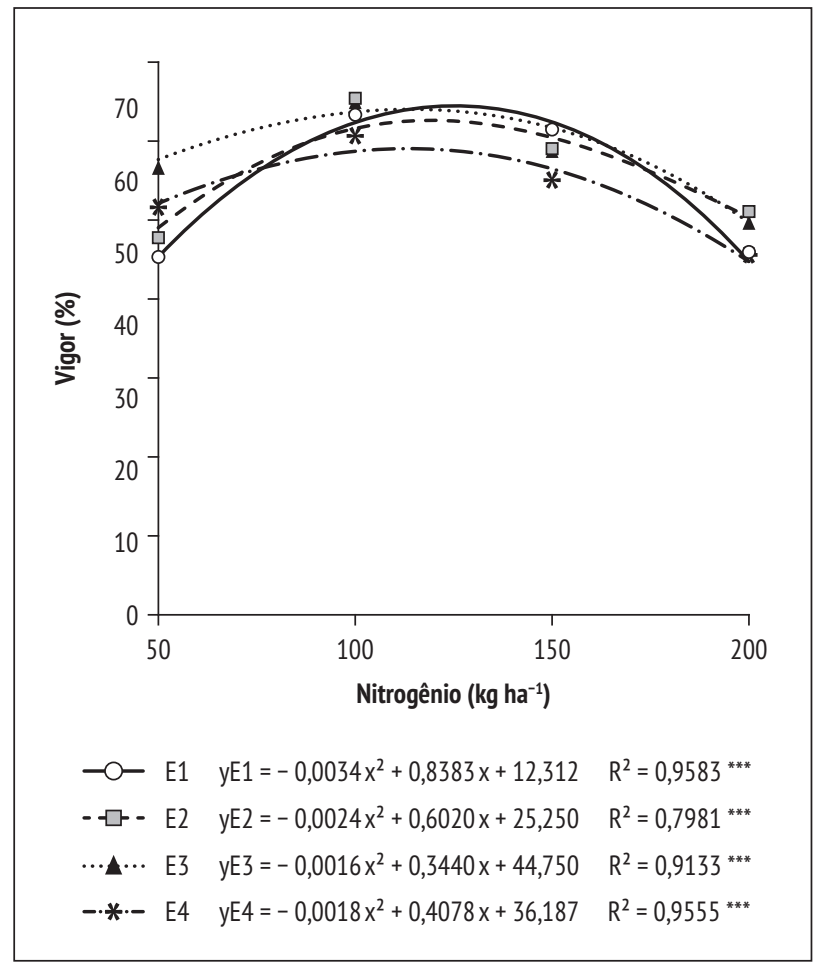

Gráfico 2 - Variação no vigor (PCG \%) de sementes de arroz irrigado (cultivar BRS Jaçanã) em função de épocas e doses de nitrogênio aplicadas

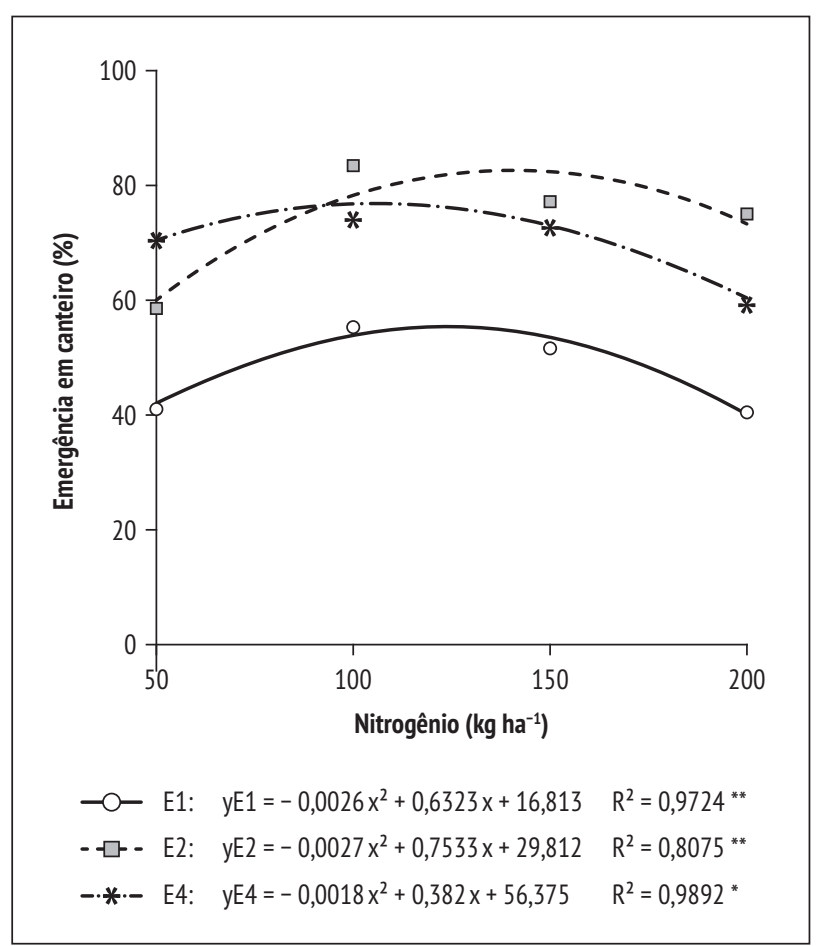

Gráfico 4 - Variação da emergência de plantas de arroz irrigado BRS Jaçanã, em canteiro, em função de épocas e doses de nitrogênio aplicadas 
Tabela 2 - Comparação de médias de umidade, vigor (PCG), germinação e emergência de plantas em canteiro de sementes de arroz irrigado cv BRS Jaçanã, produzidas em função de épocas de aplicação de nitrogênio, em área de várzea de Roraima - 2008

\begin{tabular}{lcccc}
\hline Épocas & Umidade & PCG & Germinação & Emergência em canteiro \\
\hline E1 & $10,95 \mathrm{a}$ & $53,81 \mathrm{~b}$ & $94,06 \mathrm{~b}$ & $47,56 \mathrm{~b}$ \\
E2 & $10,90 \mathrm{a}$ & $55,50 \mathrm{ab}$ & $96,13 \mathrm{a}$ & $73,81 \mathrm{a}$ \\
E3 & $10,63 \mathrm{~b}$ & $57,75 \mathrm{a}$ & $93,31 \mathrm{~b}$ & $70,25 \mathrm{a}$ \\
E4 & $10,63 \mathrm{~b}$ & $52,94 \mathrm{~b}$ & $96,94 \mathrm{a}$ & $70,38 \mathrm{a}$ \\
\hline DMS & 0,25 & 3,05 & 1,95 & 8,05 \\
\hline
\end{tabular}

Legenda: Médias seguidas das mesmas letras não diferem entre si pelo teste de Tukey a $5 \%$ de probabilidade. E1 = metade da dose na semeadura e metade aos 45 dias após a emergência (dae); E2 = metade da dose aos 15 dias e metade aos 45 dae; E3 = uma aplicação aos 15 dae e; E4 = uma aplicação aos 45 dae.

Fonte: Dados da pesquisa.

\section{Conclusões}

As épocas de aplicação de nitrogênio modificam a qualidade fisiológica das sementes. A aplicação de metade da dose de nitrogênio na semeadura e a outra aos 45 dias após a emergência provocam redução na emergência de plantas em canteiro da semente produzida.

A máxima qualidade fisiológica das sementes é obtida com a aplicação de $108 \mathrm{~kg} \mathrm{ha}^{-1}$ de nitrogênio em cobertura, aplicado em dose única aos 45 dias da emergência das plantas.

\section{Referências}

BARBOSA FILHO, M. P. Nutrição e adubação do arroz (sequeiro e irrigado). Piracicaba: Associação Brasileira para a Pesquisa da Potassa e Fósforo, 1987. (Boletim Técnico, 9).

BRASIL. Ministério da Agricultura, Pecuária e Abastecimento. Regras para análises de sementes. Brasília: Mapa/ ACS, 2009.

CARVALHO, G. J. de; OLIVEIRA, P. R. S. de; SOARES, A. A. Efeito de diferentes níveis de nitrogênio nas características agronômicas de quatro cultivares e uma linhagem de arroz irrigado (Oryza sativa L). Ciência e Prática, Lavras, v. 19, n. 4, p. 390-396, 1995.

CORDEIRO, A. C. C.; MEDEIROS, R. D. BRS Jaçanã: nova cultivar de arroz irrigado para Roraima. Boa Vista: Embrapa Roraima, 2008. (Comunicado Técnico, 2).
FAGERIA, N. K.; BARBOSA FILHO, M. P. Avaliação preliminar de cultivares de arroz irrigado para maior eficiência de utilização de nitrogênio. Pesquisa Agropecuária Brasileira, Brasília, v. 17, n. 12, p. 1709-1712, 1982.

FAGERIA, N. K.; SANTOS, A. B.; STONE, L. F. Manejo de nitrogênio em arroz irrigado. Santo Antônio de Goiás: Embrapa Arroz e Feijão, 2003. (Circular Técnica, 58).

FOX, R. L.; ALBRECHT, W. A. Soil fertility and the quality of seeds. Columbia: Missouri, 1957. (Res. Bull. Agr. Exp. Stn., 619).

LOPES, A.; GRABE, D. F. Effect of protein content to the performance in wheat. Proceedings of the Association of Official Seed Analysts, n. 63, p. 106-115, 1973.

JIANG, L. G. et al. Characterizing physiological N-use efficiency as influenced by nitrogen management in three rice cultivars. Field Crops Research, v. 88, n. 2/3, p. 239250,2004

MACHADO, M. Caracterização e adubação do solo. In: CENTRO DE PESQUISA AGROPECUÁRIA DE TERRAS BAIXAS E DE CLIMA TEMPERADO - Embrapa. Fundamentos para a cultura do arroz irrigado. Campinas: Fundação Cargil, 1985. p. 129-179.

MARSCHNER, H. Mineral nutrition of higher plants. London: Academic Press, 1995.

REIS, M. S. et al. Absorção de N, P, K, Ca, Mg e S pelo arroz irrigado influenciada pela adubação nitrogenada. Ciência e Agrotecnologia, Lavras, v. 29, n. 4, p. 707-713, 2005. 
SILVA, A. J.; MELO, V. F.; MEDEIROS, R. D. de. Limitações nutricionais para a cultura do arroz em solo de várzea do Estado de Roraima. I. Efeito sobre características agronômicas. In: FERTIBIO, 98., 1998, Caxambu. Resumos... Lavras: UFLA/SBCS/SBM, 1998. p. 562.

SOCIEDADE SUL-BRASILEIRA DE ARROZ IRRIGADO SOSBAI. Arroz irrigado: recomendações técnicas da pesquisa para o Sul do Brasil. Santa Maria: SOSBAI, 2005.

STANSEL, J. W. The rice plant: its development and yield. In: TEXAS AGRICULTURAL EXPERIMENT STATION. Six decades of rice research in Texas. College Station: Texas Agricultural Experiment Station, 1975. p. 9-21. (Research Monograph, 4).

STONE, L. F. et al. Adubação nitrogenada em arroz sob irrigação suplementar por aspersão. Pesquisa Agropecuária Brasileira, Brasília, v. 34, n. 6, p. 927-932, 1999.
SCHUCH, L. A. B.; MUNDSTOCK, C. M. Resposta de girassol a doses e ao parcelamento da aplicação de nitrogênio. Pesquisa Agropecuária Brasileira, v. 29, p. 381-387, 1994.

THAKUR, R. B. Performance of summer rice to varying levels of nitrogen. Indian Journal Agronomy, New Delhi, v. 38, n. 2, p. 187-190, 1993.

Recebido: $11 / 02 / 2010$

Received: 02/11/2010

Aprovado: 24/03/2011

Approved: 03/24/2011 